\title{
Correction to: Numerical investigation on special modes with narrow amplification diagram in harbor oscillations
}

\section{Xiaozhou Ma ${ }^{1} \cdot$ Zhenjun Zheng $^{1} \cdot$ Xiang Zhang $^{1} \cdot$ Guohai Dong ${ }^{1}$}

Published online: 22 April 2020

(C) Springer-Verlag GmbH Germany, part of Springer Nature 2020

Correction to: Ocean Dynamics (2020) 70:1-19

https://doi.org/10.1007/s10236-019-01325-8

The original version of this article, unfortunately, contained a mistake. On page 1, the first-author name below

Xiouzhou Ma

should be changed to

Xiaozhou Ma

The online version of the original article can be found at https://oi.org/ 10.1007/s10236-019-01325-8

Xiaozhou Ma

maxzh@dlut.edu.cn

1 The State Key Laboratory of Coastal and Offshore Engineering, Dalian University of Technology, Dalian 116024, Liaoning, China 